\title{
Highly Fluorescent Conducting Polymer Hybrid Materials Based on Polyaniline-Polyethylene Glycol-Arsenic Sulphide
}

\author{
Vivek Kumar Singh, Amit Singh, Vinod Kumar Gupta, Ram Adhar Singh* \\ Department of Chemistry, Centre of Advanced Study, Institute of Science, Banaras Hindu University, \\ Varanasi, India \\ Email: *prrasingh@gmail.com
}

Received 19 January 2016; accepted 27 March 2016; published 30 March 2016

Copyright (C) 2016 by authors and Scientific Research Publishing Inc.

This work is licensed under the Creative Commons Attribution International License (CC BY). http://creativecommons.org/licenses/by/4.0/

(c) (i) Open Access

\begin{abstract}
Highly fluorescent binary and ternary hybrid materials based on polyaniline, polyethylene glycol (PEG) and arsenic sulphide have been prepared via oxidative chemical polymerization and characterized by FT-IR and powder X-ray diffraction techniques. Thermogravimetric analysis showed that all the materials are thermally stable up to $250^{\circ} \mathrm{C}$. The optical behaviour was investigated using UV-Vis. and fluorescence spectroscopy. Fluorescence spectra of polyaniline and its hybrids were found to be concentration dependent, and concentrations were optimized to achieve maximum intensity of emission. Aggregation caused quenching (ACQ) may be the possible reason for concentration dependent emission. Hybrids showed significantly enhanced fluorescence than polyaniline. The AC electrical conductivity was also measured and found to be better for hybrids than the polyaniline. In the PAni-PEG-As $S_{2} S_{3}$ hybrid, the conductivity was found to be $9.57 \times 10^{-1}$ $\mathrm{S} / \mathrm{cm}$ at $100 \mathrm{KHz}$. This valuable improvement in luminescent property and conducting behaviour may be useful in various optoelectronic and electronic applications.
\end{abstract}

\section{Keywords}

Polyaniline Hybrids, Fluorescence, Aggregation Caused Quenching (ACQ), Electrical Conductivity, Opto-Electronic Applications

\section{Introduction}

Conjugated conducting polymers have recently received special attention in nanoscience and nanotechnology "Corresponding author.

How to cite this paper: Singh, V.K., Singh, A., Gupta, V.K. and Singh, R.A. (2016) Highly Fluorescent Conducting Polymer Hybrid Materials Based on Polyaniline-Polyethylene Glycol-Arsenic Sulphide. International Journal of Organic Chemistry, 6, 55-64. http://dx.doi.org/10.4236/ijoc.2016.61006 
because of their highly $\pi$-conjugated polymeric chains and metal like conductivity [1]-[4]. The optical properties of conducting polymers [5]-[7] are as important as electrical properties because they allow number of applications such as sensing [8]-[10], displays and other opto-electronic applications [11] [12]. Along with various advantages, these pristine conducting polymers have several drawbacks such as poor emission, processability and stability. However, these drawbacks could be overcome to a large extent by preparing their hybrids with inorganic semiconductors such as metal sulfides and oxides. In the past, hybrids of polyaniline with various micro/ nano structural semiconductors such as $\mathrm{ZnS}$, $\mathrm{CdS}, \mathrm{Bi}_{2} \mathrm{~S}_{3}$ have been prepared and studied for their various properties [13]-[17]. The combinations of organic and inorganic species create new material for development of new multifunctional devices [18]-[20]. It improves mechanical, optical, electrical and other properties of material. In conducting polymer, polyaniline is cheap, easily synthesizable and has high environmental stability. So, polyaniline has been frequently used as a host material for hybrids with various metallic sulfides [21] [22].

The structural photoelectrical properties of $\mathrm{PAni} / \mathrm{Bi}_{2} \mathrm{~S}_{3}$ composite thin film prepared by electrodeposition have been studied. It was found that with the increase in concentration of PAni in PAni/ $/ \mathrm{Bi}_{2} \mathrm{~S}_{3}$ hybrid, conductivity increases [23]. NiS/PAni counter electrode showed excellent electro catalytic activity and low charge transfer resistance relative to that of a platinum counter electrode in sulfide/polysulfide $\left(\mathrm{S}^{2-} / \mathrm{S}^{3-}\right)$ electrolyte [24]. The photoluminescence and Raman evidence for mechanic-chemical interaction of polyaniline-emeraldine base with $\mathrm{ZnS}$ in cubic and hexagonal phase have also been reported [25].

In present work, binary/ternary hybrids of polyaniline with PEG and $\mathrm{As}_{2} \mathrm{~S}_{3}$ were synthesized by in situ polymerization of aniline in acidic medium. All the materials were characterized for their spectral, thermal, optical and electrical properties. Luminescence behaviour of polyaniline and its hybrids were investigated at different concentration in dimethylsulphoxide (DMSO). To the best of our knowledge no reports have been found related to synthesis and optical properties of ternary hybrid of PAni with $\mathrm{As}_{2} \mathrm{~S}_{3}$-PEG.

\section{Experimental Section}

\subsection{Materials and Methods}

Aniline (Merck, A.R. grade) was distilled twice at normal pressure before use. Polyethylene glycol 6000 (Average molecular weight 7000 - 9000, LOBA chemicals, A. R. grade); arsenic sulfide (Merck) and ammonium persulphate (Merck) were used as received. Triple distilled water was used in all the synthesis processes.

\subsection{Synthesis}

Polyaniline was prepared by standard procedure [13]. Syntheses of various hybrids are stated below:

\subsubsection{Synthesis of Polyaniline-Polyethylene Glycol (PAni-PEG) Hybrid}

To the solution of aniline ( $3 \mathrm{~g}, 0.03 \mathrm{~mol}$ ) dissolved in $60 \mathrm{~mL} 2 \mathrm{~N} \mathrm{HCl}, 1.0 \mathrm{~g}$ polyethylene glycol dissolved in 25 $\mathrm{mL}$ water solution was added, mixed thoroughly and cooled below $5^{\circ} \mathrm{C}$ in an ice bath. Ammonium per sulfate $9.0 \mathrm{~g}(0.07 \mathrm{~mol})$ dissolved in $60 \mathrm{~mL}$ water was added slowly in an hour along with continuous stirring. The green color precipitate was obtained, kept in freezer over night, filtered, washed and dried. Yield (in g) = 3.1 g.

\subsubsection{Synthesis of Polyaniline-Arsenic Sulfide (PAni- $\left.\mathrm{As}_{2} \mathrm{~S}_{3}\right)$ Hybrid}

Aniline, $3.0 \mathrm{~g}$ ( $0.03 \mathrm{~mol})$ was dissolved in $60 \mathrm{~mL} 2 \mathrm{~N} \mathrm{HCl}$ and kept in ice bath. $2.0 \mathrm{~g}(0.05 \mathrm{~mol})$ arsenic trioxide was dissolved in $200 \mathrm{~mL} 2 \mathrm{~N} \mathrm{HCl}$ and then $\mathrm{H}_{2} \mathrm{~S}$ was passed for 15 minutes. A yellow colored colloidal $\mathrm{As}_{2} \mathrm{~S}_{3}$ solution was obtained which was cooled to the temperature of less than $5^{\circ} \mathrm{C}$. A pre-cooled solution of $9.0 \mathrm{~g}(0.07$ mol) of ammonium per sulfate dissolved in $60 \mathrm{~mL}$ water was added slowly by burette in aniline hydrochloride and arsenic sulfide colloidal mixture with continuous stirring. After 30 minutes a green colored precipitate started to form indicating the initiation of the reaction. The reaction was allowed to proceed for an hour, and then the mixture was kept in freezer overnight. A bluish green color precipitate was obtained. The precipitate was filtered and washed with $2 \mathrm{~N} \mathrm{HCl}$ and thrice by triple distilled water in order to remove unreacted reagents. The precipitate was dried in an oven at $60^{\circ} \mathrm{C}-70^{\circ} \mathrm{C}$ and then kept over anhydrous $\mathrm{CaCl}_{2}$ in desiccator. Yield (in g) $=3.5 \mathrm{~g}$.

\subsubsection{Polyaniline-Polyethylene Glycol-Arsenic Sulfide (PAni-PEG-As $\mathrm{S}_{3}$ ) Hybrid} $2.0 \mathrm{~g}(0.05 \mathrm{~mol})$ arsenic trioxide dissolved in $200 \mathrm{~mL} 2 \mathrm{~N} \mathrm{HCl}$ and $\mathrm{H}_{2} \mathrm{~S}$ was passed into the solution for 15 minutes. 
To the resulting colloidal solution, aniline $3 \mathrm{~g}(0.03 \mathrm{~mol})$ dissolved in $60 \mathrm{~mL} 2 \mathrm{~N} \mathrm{HCl}$ and 1.0 g polyethylene glycol dissolved in $25 \mathrm{~mL}$ water solution was added, mixed thoroughly and cooled below $5^{\circ} \mathrm{C}$ in an ice bath. Ammonium per sulfate $9.0 \mathrm{~g}(0.07 \mathrm{~mol})$ dissolved in $60 \mathrm{~mL}$ water was added slowly in an hour along with continuous stirring. The green color precipitate was kept in freezer over night, filtered washed and dried. Yield (in g) $=4.5 \mathrm{~g}$. There were no yellow colored particles of $\mathrm{As}_{2} \mathrm{~S}_{3}$ present in the prepared hybrid indicating good coating of $\mathrm{As}_{2} \mathrm{~S}_{3}$ nanoparticles by polyaniline. The overall synthesis process is shown in Figure 1.

\subsection{Measurements}

IR spectra of the samples were recorded using PerkinElmer FTIR Spectrometer as KBr pellets. UV-Visible spectra were recorded on a Shimadzu UV-1700 spectrophotometer. Fluorescence spectral measurements were carried out on a JY Horiba fluorescence spectrophotometer. The thermo gravimetric analysis (TGA) measurements were performed on Perkin Elmer STA 600 at heating rate of $10^{\circ} \mathrm{C}$ per minute. AC impedance/conductance in the frequency range of $40 \mathrm{~Hz}$ to $100 \mathrm{KHz}$ was made using a LCZ meter (Keithley 3330). The basic accuracy of the LCZ meter used for our measurements was $0.1 \%$ for the impedances in the range of $0.1 \mathrm{~m} \Omega$ to $19.999 \mathrm{M} \Omega$; capacitances in the range of $0.001 \mathrm{pF}$ to $199.99 \mathrm{mF}$ and for conductance in the range of $0.001 \mu \mathrm{S}$ to $199.99 \mathrm{~S}$.

\section{Results and Discussion}

\subsection{IR Spectroscopy}

IR spectra of the samples were recorded in the range $400-4000 \mathrm{~cm}^{-1}$ in $\mathrm{KBr}$ medium. The IR spectra of the hybrids and PAni have been shown in Figure 2 and all the characteristic bands are tabulated in Table 1. A broad

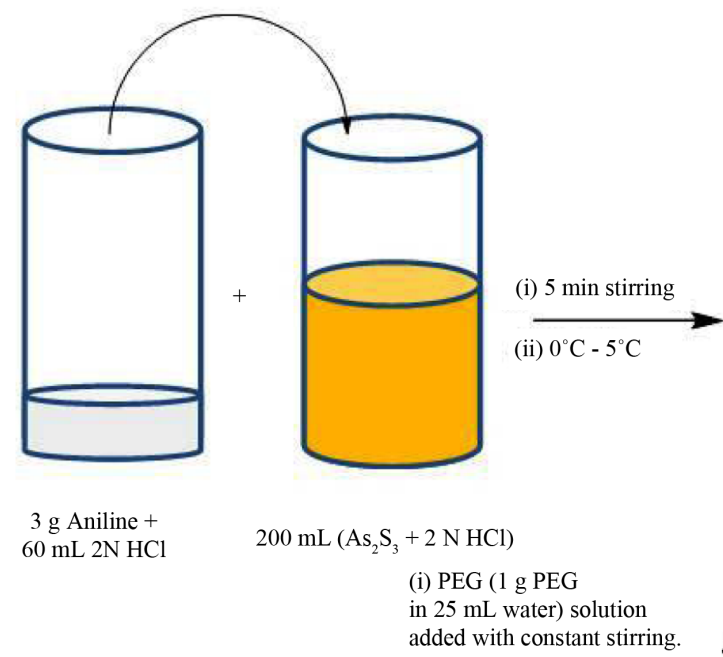

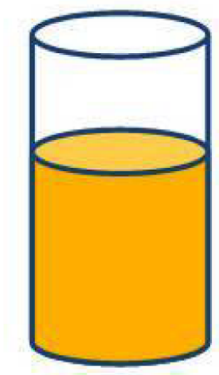

Aniline $+\mathrm{As}_{2} \mathrm{~S}_{3}$

(ii) APS solution added drop by drop with contant stirring and solution was stirred $50 \mathrm{~min}$ after adding APS.

(iii) $0^{\circ} \mathrm{C}-5^{\circ} \mathrm{C}$
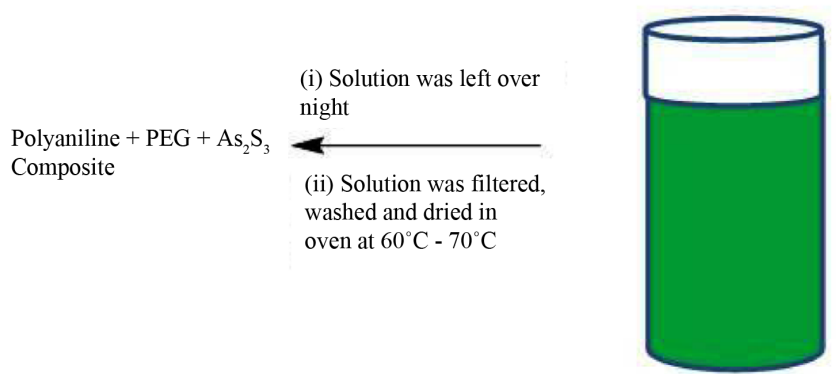

Green colour precipitate obtained 


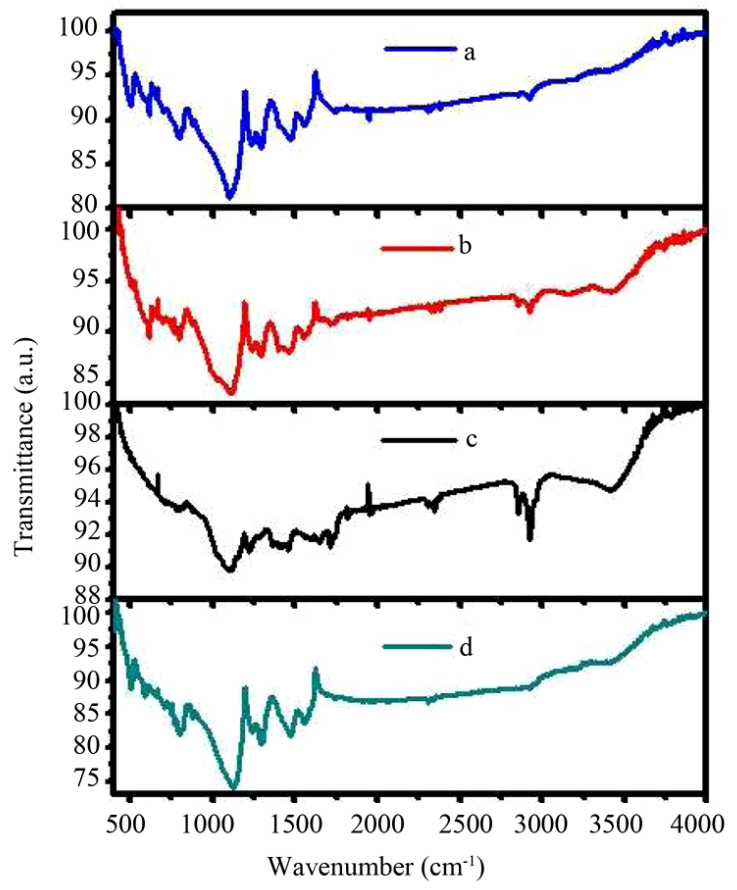

Figure 2. Infra-red spectra of (a) PAni, (b) PAni-PEG, (c) PAni-As $\mathrm{S}_{3}$ and (d) PAni-PEG-As $\mathrm{S}_{3}$.

Table 1. Characteristics of I. R. (in $\mathrm{cm}^{-1}$ ) of (a) PAni, (b) PAni-PEG, (c) PAni-As $\mathrm{S}_{3}$ and (d) PAni-PEG-As $\mathrm{S}_{3}$.

\begin{tabular}{cccccc}
\hline Sample & Quinoid & Benzenoid & (C-N) stret. & (C-C) stret. & (C-H) (op) \\
\hline PAni & 1555 & 1468 & 1292 & 1105 & 796 \\
PAni-PEG & 1556 & 1463 & 1293 & 1107 & 791 \\
PAni-As $2 S_{3}$ & 1558 & 1451 & 1285 & 1100 & 795 \\
PAni-PEG-As $S_{3}$ & 1558 & 1469 & 1296 & 1122 & 802 \\
\hline
\end{tabular}

band comes at the region of $3415-3460 \mathrm{~cm}^{-1}$ is due to $v(\mathrm{~N}-\mathrm{H})$ stretching mode. The vibrational bands at 1563 $\mathrm{cm}^{-1}$ correspond to stretching of $v(\mathrm{~N}=\mathrm{Q}=\mathrm{N})$ where $\mathrm{Q}$ refers to $\mathrm{C}_{6} \mathrm{H}_{4}$ in quinoid form and the band at $1490 \mathrm{~cm}^{-1}$ $v$ (N-B-N) where B refers to $\mathrm{C}_{6} \mathrm{H}_{4}$ in benzenoid form. The bands at $1300 \mathrm{~cm}^{-1}$ are assigned to C-N stretching vibration in QBQ and QBC, QBB, BBQ and the band at $1240 \mathrm{~cm}^{-1}$ is due to C-N stretching vibration of aromatic amine. In the region of $1020-1170 \mathrm{~cm}^{-1}$ the aromatic C-H in plane bending while the bands at $803 \mathrm{~cm}^{-1}$ is due to C-H out of plane bending of 1, 4 disubstituted benzene are observed. A strong band comes at 1140 $\mathrm{cm}^{-1}$ due to electronic band or vibrational band at pure nitrogen quinine in polyaniline. A band at $703 \mathrm{~cm}^{-1}$ is assigned to the ring $\mathrm{C}-\mathrm{C}$ bending vibration, while the band at $590 \mathrm{~cm}^{-1}$ is due to the ring in plane deformation. The $\mathrm{C}-\mathrm{H}$ out of plane bending mode has been used as a key to identify the type of substituted benzene. A band at $500 \mathrm{~cm}^{-1}$ is assigned to aromatic ring deformation.

A very good agreement between these spectra of PAni and hybrids, indicating that biomimetic synthesis leads to hybrid material based on these systems. The bands at $1468 \mathrm{~cm}^{-1}$ were found to undergo a red shift to 1451 $\mathrm{cm}^{-1}$ in presence of $\mathrm{As}_{2} \mathrm{~S}_{3}$ long with similar shifts from 1105 to $1000 \mathrm{~cm}^{-1}$ and 796 to $795 \mathrm{~cm}^{-1}$. The interaction of cationic anilinium ions with anionic $\mathrm{As}_{2} \mathrm{~S}_{3}$ colloidal particle may be responsible for bringing $\mathrm{As}_{2} \mathrm{~S}_{3}$ particles close to the nitrogen sites which lead to weak interactions between the conjugated polyaniline shells with nonconducting $\mathrm{As}_{2} \mathrm{~S}_{3}$ core.

\subsection{X-Ray Diffraction Studies}

The powder X-ray diffraction is one of the best methods to find out incorporation of additive into the host material 
i.e. in the case of binary and ternary hybrids. The X-Ray Diffraction pattern of PAni, PAni-PEG, PAni- $\mathrm{As}_{2} \mathrm{~S}_{3}$ and PAni-PEG- $\mathrm{As}_{2} \mathrm{~S}_{3}$ are shown in Figure 3. It shows broad and well defined peaks, which indicate the semi crystalline nature of all the materials. The plains of benzenoid and quinoid rings of PAni chain are responsible for semi crystalline nature. As per various reports present in literature, $\mathrm{As}_{2} \mathrm{~S}_{3}$ exhibit peaks at about $33^{\circ}$ and $54^{\circ}$. The similar peaks were observed in PAni- $\mathrm{As}_{2} \mathrm{~S}_{3}$ and PAni-PEG- $\mathrm{As}_{2} \mathrm{~S}_{3}$ hybrids which clearly indicate the presence of $\mathrm{As}_{2} \mathrm{~S}_{3}$ in hybrids. It is also clear from the XRD patterns that crystallinity decreases from polyaniline to its hybrids as intensity of the peaks decreases. PAni encapsulates $\mathrm{As}_{2} \mathrm{~S}_{3}$ particles, interaction of PAni and $\mathrm{As}_{2} \mathrm{~S}_{3}$ weaken the interaction between two PAni chains and thus crystallinity of PAni is hampered and the degree of crystallinity decreases.

\subsection{Thermogravimetric Analysis}

Thermal degradation patterns of the PAni and various hybrids have been displayed in Figure 4. From the pattern it is clear that they follow a three-stage decomposition pattern. The first stage being weight loss, starting from room temperature to $100.0^{\circ} \mathrm{C}$ corresponds to loss of water molecules/moisture present in the polymer. The second stage loss from $100.0^{\circ} \mathrm{C}$ to $250.0^{\circ} \mathrm{C}$ is associated with a loss of dopant ion from the polymer matrix (dedoping). However, the weight loss after $250.0^{\circ} \mathrm{C}$ is due to degradation and decomposition of the polymer after the loss of dopant ion. PAni, PAni-PEG, PAni-As ${ }_{2} \mathrm{~S}_{3}$ and PAni-PEG- $\mathrm{As}_{2} \mathrm{~S}_{3}$ exhibit weight loss $15 \%, 18 \%, 19 \%$ and $20 \%$, respectively in the temperature range $100^{\circ} \mathrm{C}-250^{\circ} \mathrm{C}$. The total weight loss up to $800^{\circ} \mathrm{C}$ of PAni, PAni-PEG, PAni- $\mathrm{As}_{2} \mathrm{~S}_{3}$ and PAni-PEG- $\mathrm{As}_{2} \mathrm{~S}_{3}$ are $54 \%, 56 \%$, 66\%and $69 \%$, respectively. It indicates that up to $200.0^{\circ} \mathrm{C} \mathrm{As}_{2} \mathrm{~S}_{3}$ hybrids have less weight loss than PAni and PAni-PEG but above $250^{\circ} \mathrm{C}$ hybrids have larger weight loss than PAni and PAni-PEG. The cause behind temperature drop in hybrid at higher temperature region could be attributed to a strong interaction at the interface of $\mathrm{AS}_{2} \mathrm{~S}_{3}$ and PAni weaken the force of interaction of PAni interchains and enhance thermal decomposition of PAni in the hybrid.

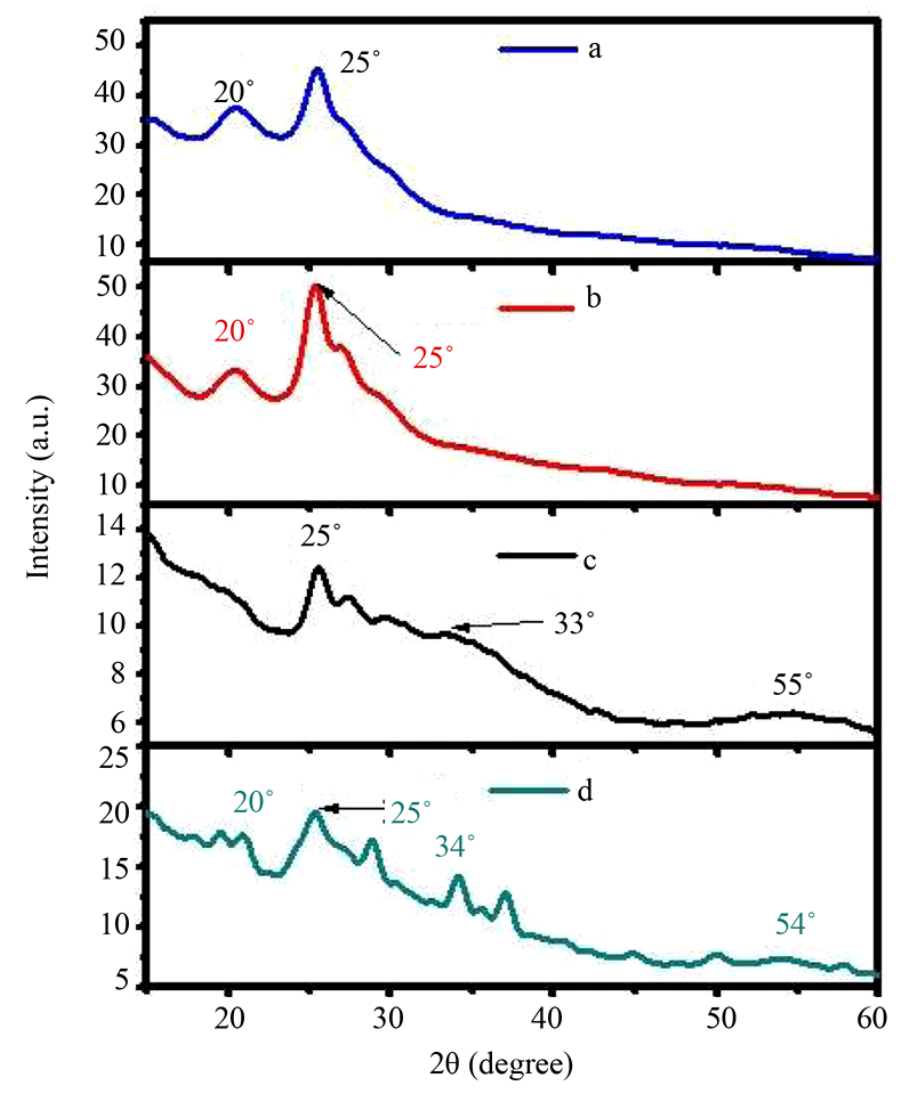

Figure 3. Powder X-ray diffraction patterns of (a) PAni, (b) PAni-PEG, (c) PAni- $\mathrm{As}_{2} \mathrm{~S}_{3}$ and (d) PAni-PEG- $\mathrm{As}_{2} \mathrm{~S}_{3}$. 


\subsection{UV-Visible Spectra}

The UV-Visible absorption spectra are helpful to identify extent of conjugation in conducting polymers and also in comparative study of conducting polymers with their hybrids. The absorption spectra of PAni and various hybrids were recorded in DMSO solution and given in Figure 5.

The absorption spectrum of PAni exhibits band at $645 \mathrm{~nm}$, indicates high degree of conjugation. However, these bands have been found slightly blue shifted in the case of hybrids. The obtained values are tabulated in

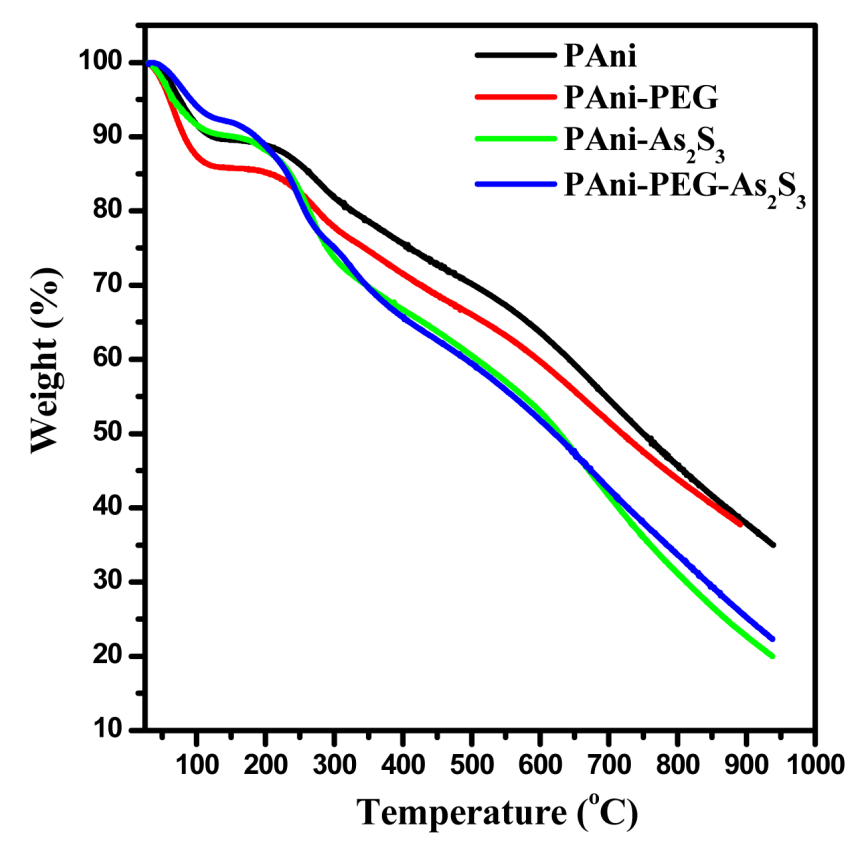

Figure 4. TGA curves of PAni, PAni-PEG, PAni- $\mathrm{As}_{2} \mathrm{~S}_{3}$ and PA$\mathrm{ni}-\mathrm{PEG}-\mathrm{As}_{2} \mathrm{~S}_{3}$.

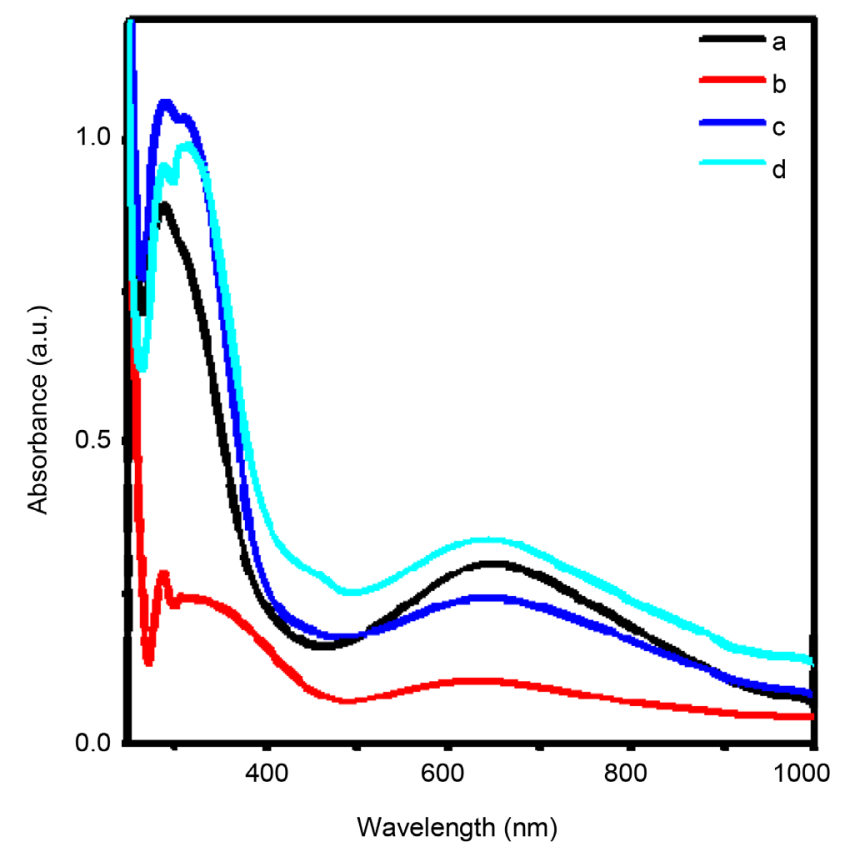

Figure 5. UV-visible spectra of (a) PAni, (b) PAni-PEG, (c) PAni- $\mathrm{As}_{2} \mathrm{~S}_{3}$ and (d) PAni-PEG- $\mathrm{As}_{2} \mathrm{~S}_{3}$. 
Table 2. The blue shifting in hybrids depend upon the amount of the PAni. Higher the amount of PAni lesser will be the shifting of these bands. In the absorption spectra of hybrids, the band appears at the lower wavelength region also suffer blue shift in respect to PAni. It may be due to the microstructural changes which depend on the synthetic conditions.

\subsection{Fluorescence Studies}

The fluorescence spectra of PAni, PAni-PEG, PAni- $\mathrm{As}_{2} \mathrm{~S}_{3}$ and PAni-PEG- $\mathrm{As}_{2} \mathrm{~S}_{3}$ were recorded in DMSO. All the materials showed significant emission in the range of $300-550 \mathrm{~nm}$. In order to achieve optimum concentration, the fluorescence spectra were recorded at different concentrations and are shown in Figure 6.

Table 2. UV-visible spectral bands of (a) PAni, (b) PAni-PEG, (c) PAni- $-\mathrm{As}_{2} \mathrm{~S}_{3}$ and (d) PAni-PEG- $\mathrm{As}_{2} \mathrm{~S}_{3}$.

\begin{tabular}{cccc}
\hline Samples & $\lambda^{\text {abs }}\left(\pi \rightarrow \pi^{*}\right.$ band $)(\mathrm{nm})$ & $\lambda^{\text {abs }}($ Exiton band $)(\mathrm{nm})$ & $\lambda^{\text {emi }}(\mathrm{nm})$ \\
\hline PAni & 292 & 645 & 345 \\
PAni-PEG & 287 & 630 & 343 \\
PAni-As $\mathrm{S}_{3}$ & 290 & 641 & 411 \\
PAni-PEG-As $\mathrm{S}_{3}$ & 289 & 641 & 392 \\
\hline
\end{tabular}

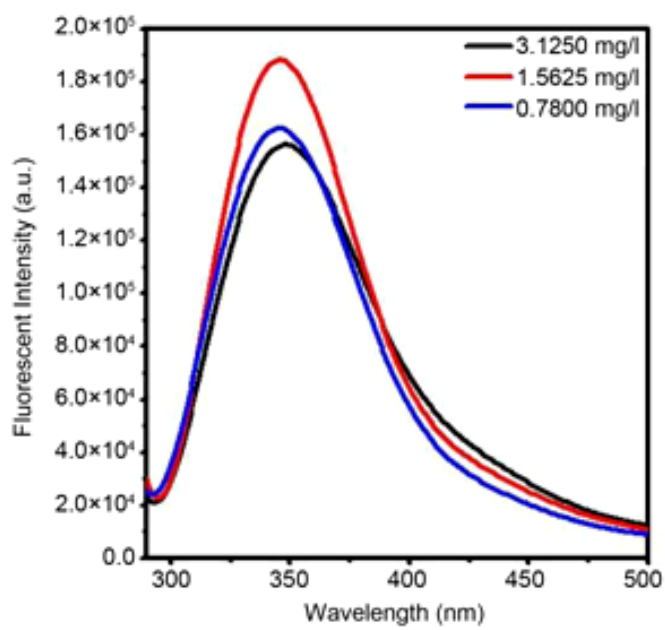

(a)

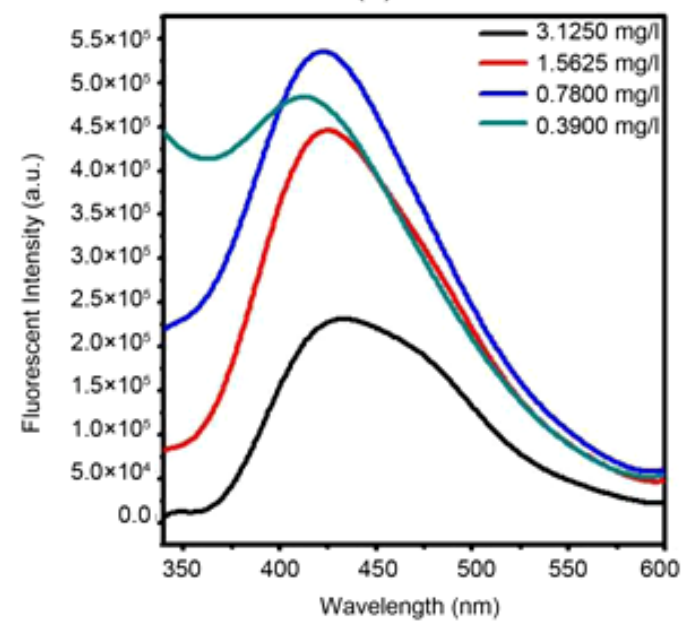

(c)

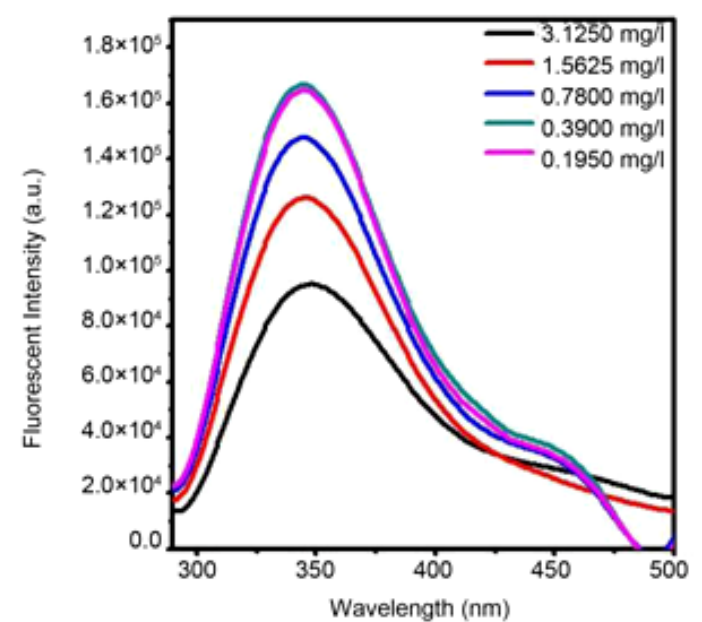

(b)

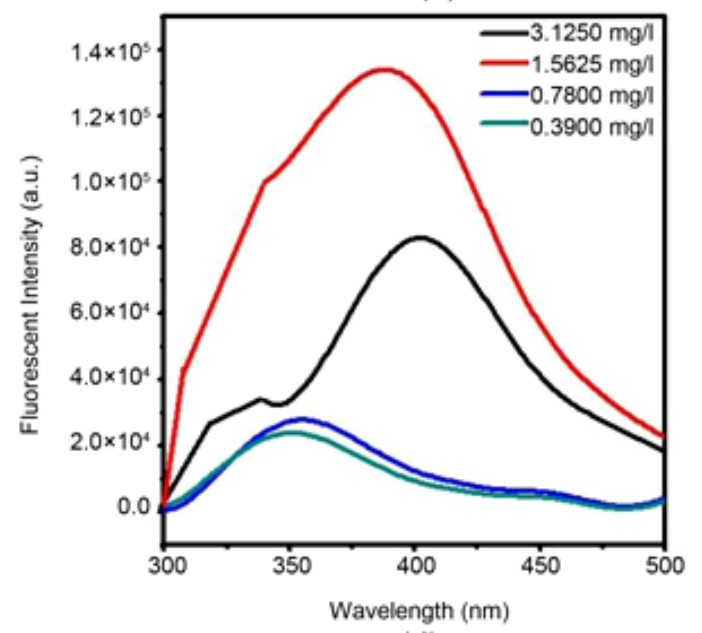

(d)

Figure 6. Fluorescence spectra of (a) PAni, (b) PAni-PEG, (c) PAni-As $\mathrm{S}_{3}$ and (d) PAni-PEG-As $\mathrm{S}_{3}$. 
Above optimum concentration, the fluorescence intensity decreases due aggregation caused quenching (ACQ) and below optimum concentration it decreases due to much dilution. From concentration versus fluorescence intensity curve (Figure 7), it is clear that PAni-PEG- $\mathrm{As}_{2} \mathrm{~S}_{3}$ hybrid showed highest emission among all. Also, PAni exhibits weaker emission than hybrids, might be due to presence of additives may reduce the possibility of aggregation in PAni.

\subsection{AC Electrical Conductivity Measurement}

The AC electrical conductivity of PAni and various hybrids were measured at room temperature in the various frequency regions using platinum foils as contacts on pellets. The values are represented in Table 3 . In all the cases, with increase in frequency conductivity of the materials increases.

At $100 \mathrm{~Hz}$, the conductivity of polyaniline was found to be $4.08 \times 10^{-1} \mathrm{~S} / \mathrm{cm}$. In the PAni-PEG- $\mathrm{As}_{2} \mathrm{~S}_{3}$ hybrid the conductivity was found to be $9.53 \times 10^{-1} \mathrm{~S} / \mathrm{cm}$. The conductivity of PAni-PEG-As $\mathrm{S}_{3}$ hybrid is also measured as a function of temperature. It has been found that, an increase in temperature results into increase in conductivity and shows the semiconductor behavior of material. Arrhenius plot is shown in Figure 8.

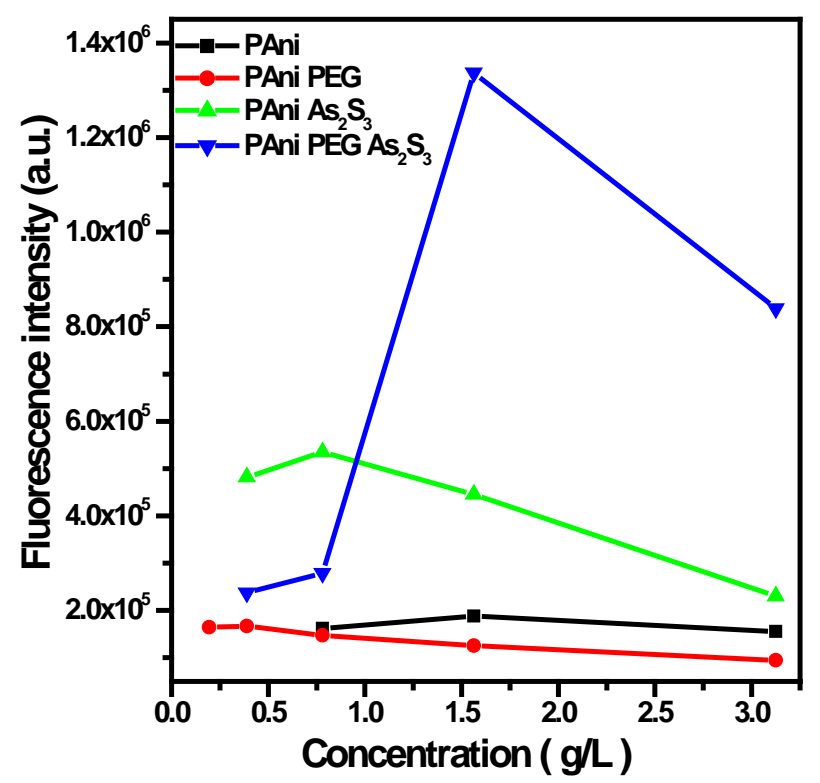

Figure 7. Concentration vs. fluorescence intensity plots for PAni, PAni-PEG, PAni- $\mathrm{As}_{2} \mathrm{~S}_{3}$ and PAni-PEG-As $\mathrm{S}_{3}$.

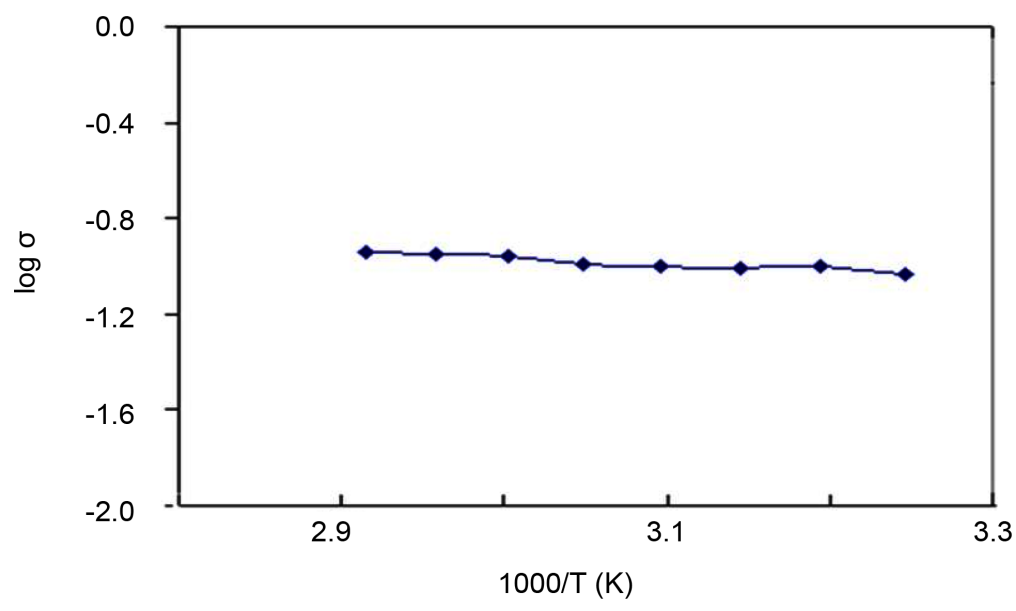

Figure 8. Arrhenius plot for PAni-PEG- $\mathrm{As}_{2} \mathrm{~S}_{3}$ hybrid. 
Table 3. Conductivity data summary of polyaniline and hybrids.

\begin{tabular}{cccc}
\hline Composition & $\sigma_{a c}(\mathrm{~S} / \mathrm{cm}) 100 \mathrm{~Hz}$ & $\sigma_{a c}(\mathrm{~S} / \mathrm{cm}) 1 \mathrm{KHz}$ & $\sigma_{a c}(\mathrm{~S} / \mathrm{cm}) 100 \mathrm{KHz}$ \\
\hline PAni & $4.08 \times 10^{-1}$ & $4.40 \times 10^{-1}$ & $4.42 \times 10^{-1}$ \\
PAni-PEG & $3.98 \times 10^{-2}$ & $4.28 \times 10^{-2}$ & $4.39 \times 10^{-2}$ \\
PAni-As $_{2} \mathrm{~S}_{3}$ & $4.66 \times 10^{-2}$ & $4.88 \times 10^{-2}$ & $4.98 \times 10^{-2}$ \\
PAni-PEG-As $\mathrm{S}_{3}$ & $9.18 \times 10^{-1}$ & $9.53 \times 10^{-1}$ & $9.57 \times 10^{-1}$ \\
\hline
\end{tabular}

\section{Conclusion}

In conclusion, polyaniline based binary and ternary hybrids were prepared and exhibited better luminescent and conducting properties than polyaniline. Luminescent spectra of polyaniline and its hybrids were taken at different concentration in DMSO and found to be concentration dependent. Fluorescence signals of polyaniline and its hybrids were found to be aggregation caused quenching (ACQ) type. Powder X-ray diffraction pattern revealed that hybrids of PAni exhibit poor crystallinity than PAni. Ternary hybrid, PAni-PEG-As $\mathrm{S}_{3}$, posses highest conductivity among all the materials. These materials may find potential application in electronic and optoelectronic devices.

\section{Acknowledgements}

V. K. Singh is thankful to the Council of Scientific and Industrial Research (CSIR), New Delhi for senior research fellowship (SRF). V. K. Gupta is thankful to the University Grant Commission (UGC), New Delhi for the award of BSR meritorious fellowship.

\section{References}

[1] Deng, H., Lin, L., Ji, M., Zhang, S., Yang, M. and Fu, Q. (2014) Progress on the Morphological Control of Conductive Network in Conductive Polymer Composites and the Use as Electroactive Multifunctional Materials. Progress in Polymer Science, 39, 627-655. http://dx.doi.org/10.1016/j.progpolymsci.2013.07.007

[2] Muhsin, B., Roesch, R., Gobsch, G. and Hoppe, H. (2014) Flexible ITO-Free Polymer Solar Cells Based on Highly Conductive PEDOT: PSS and a Printed Silver Grid. Solar Energy Materials and Solar Cells, 130, 551-554. http://dx.doi.org/10.1016/j.solmat.2014.08.009

[3] Shi, Y., Pan, L., Liu, B., Wang, Y., Cui, Y., Bao, Z. and Yu, G. (2014) Nanostructured Conductive Polypyrrolehydrogels as High-Performance, Flexible Supercapacitor Electrodes. Journal of Materials Chemistry A, 2, 6086-6091. http://dx.doi.org/10.1039/c4ta00484a

[4] Mutiso, R.M. and Winey, K.I. (2015) Electrical Properties of Polymer Nanocomposites Containing Rod-Like Nanofillers. Progress in Polymer Science, 40, 63-84. http://dx.doi.org/10.1016/j.progpolymsci.2014.06.002

[5] Hriz, K., Jaballah, N., Fave, J.L. and Majdoub, M. (2015) New Anthracene-Based Semi-Conducting Polymer Analogue of Poly(phenylene sulfide): Synthesis and Photophysical Properties. Optical Materials, 46, 401-408 http://dx.doi.org/10.1016/j.optmat.2015.04.055

[6] Adachi, N., Kaneko, Y., Sekiguchi, K., Sugiyama, H. and Sugeno, M. (2015) pH-Responsive Fluorescence Chemical Sensor Constituted by Conjugated Polymers Containing Pyridine Rings. Luminescence, 30, 1308-1312 http://dx.doi.org/10.1002/bio.2898

[7] Sun, H., Lu, B., Duan, X., Xu, J., Dong, L., Zhu, X. and Ming, S. (2015) Electrosynthesis and Characterization of a New Conducting Copolymer from 2'-Aminomethyl-3,4-ethylenedioxythiophene and 3,4-Ethylenedioxythiophene. International Journal of Electrochemical Science, 10, 3236-3249.

[8] Sheng, G., Xu, G., Xu, S., Wang, S. and Luo, X. (2015) Cost-Effective Preparation and Sensing Application of Conducting Polymer PEDOT/Ionic Liquid Nanocomposite with Excellent Electrochemical Properties. RSC Advances, 5, 20741-20746. http://dx.doi.org/10.1039/C4RA15755A

[9] Verma, R. and Gupta, B.D. (2015) Detection of Heavy Metal Ions in Contaminated Water by Surface Plasmon Resonance Based Optical Fiber Sensor Using Conducting Polymer and Chitosan. Food Chemistry, 166, 568-575. http://dx.doi.org/10.1016/j.foodchem.2014.06.045

[10] Hui, N., Wang, S., Xie, H., Xu, S., Niu, S. and Luo, X. (2015) Nickel Nanoparticles Modified Conducting Polymer Composite of Reduced Graphene Oxide Doped Poly(3,4-ethylenedioxythiophene) for Enhanced Nonenzymatic Glucose Sensing. Sensors and Actuators B: Chemical, 221, 606-613. http://dx.doi.org/10.1016/j.snb.2015.07.011 
[11] Qiu, T., Luo, B., Liang, M., Ning, J., Wang, B., Li, X. and Zhi, L. (2015) Hydrogen Reduced Graphene Oxide/Metal Grid Hybrid Film: Towards High Performance Transparent Conductive Electrode for Flexible Electrochromic Devices. Carbon, 81, 232-238. http://dx.doi.org/10.1016/j.carbon.2014.09.054

[12] Soganci, T., Kurtay, G., Ak, M. and Güllü, M. (2015) Preparation of an EDOT-Based Polymer: Optoelectronic Properties and Electrochromic Device Application. RSC Advances, 5, 2630-2639. http://dx.doi.org/10.1039/C4RA13060J

[13] Singh, A., Singh, N.P., Singh, P. and Singh, R.A. (2011) Synthesis and Characterization of Conducting Polymer Composites Based on Polyaniline-Polyethylene Glycol-Zinc Sulfide System. Journal of Polymer Research, 18, 67-77. http://dx.doi.org/10.1007/s10965-010-9392-6

[14] Xiao, Y., Wang, W.Y., Chou, S.W., Lin, T.W. and Lin, J.Y. (2014) In Situ Electropolymerization of Polyaniline/Cobalt Sulfide Decorated Carbon Nanotube Composite Catalyst toward Triiodide Reduction in Dye-Sensitized Solar Cells. Journal of Power Sources, 266, 448-455. http://dx.doi.org/10.1016/j.jpowsour.2014.05.037

[15] Yang, P., Duan, J. and Tang, Q. (2015) Cobalt Sulfide Decorated Polyaniline Complex Counter Electrodes for Efficient Dye-Sensitized Solar Cells. Electrochimica Acta, 184, 64-69. http://dx.doi.org/10.1016/j.electacta.2015.10.050

[16] Shit, A., Chatterjee, S. and Nandi, A.K. (2014) Dye-Sensitized Solar Cell from Polyaniline-ZnS Nanotubes and Its Characterization through Impedance Spectroscopy. Physical Chemistry Chemical Physics, 16, 20079-20088. http://dx.doi.org/10.1039/C4CP02175D

[17] Dey, S.K. and Sarkar, D. (2014) Effect of Zn Source Concentration on Structural, Optical and Electrical Properties of zinc Sulphide-Polyaniline (ZnS-PANI) Nanocomposite Thin Films. Journal of Materials Science: Materials in Electronics, 25, 5638-5645. http://dx.doi.org/10.1007/s10854-014-2353-9

[18] Shin, K.Y., Kim, M., Lee, J.S. and Jang, J. (2015) Highly Omnidirectional and Frequency Controllable Carbon/ Polyaniline-Based 2D and 3D Monopole Antenna. Scientific Reports, 5, Article No.: 13615.

[19] Wu, J., Yang, Z., Chen, N., Zhu, W., Hong, J., Huang, C. and Zhou, X. (2015) Vanillin-Molecularly Targeted Extraction of Stir Bar Based on Magnetic Field Induced Self-Assembly of Multifunctional $\mathrm{Fe}_{3} \mathrm{O}_{4} @$ Polyaniline Nanoparticles for Detection of Vanilla-Flavor Enhancers in Infant Milk Powders. Journal of Colloid and Interface Science, 442, 22-29. http://dx.doi.org/10.1016/j.jcis.2014.11.025

[20] Islam, M.M., Aboutalebi, S.H., Cardillo, D., Liu, H.K., Konstantinov, K. and Dou, S.X. (2015) Self-Assembled Multifunctional Hybrids: Toward Developing High-Performance Graphene-Based Architectures for Energy Storage Devices. ACS Central Science, 1, 206-216. http://dx.doi.org/10.1021/acscentsci.5b00189

[21] He, K., Li, M. and Guo, L. (2012) Preparation and Photocatalytic Activity of PANI-CdS Composites for Hydrogen Evolution. International Journal of Hydrogen Energy, 37, 755-759. http://dx.doi.org/10.1016/j.ijhydene.2011.04.065

[22] Sasikala, R., Gaikwad, A.P., Jayakumar, O.D., Girija, K.G., Rao, R., Tyagi, A.K. and Bharadwaj, S.R. (2015) Nanohybrid $\mathrm{MoS}_{2}$-PANI-CdS Photocatalyst for Hydrogen Evolution from Water. Colloids and Surfaces A: Physicochemical and Engineering Aspects, 481, 485-492. http://dx.doi.org/10.1016/j.colsurfa.2015.06.027

[23] Subramanian, S. and Padiyan, D.P. (2009) Inclusion of Polyaniline in Electrodeposited Bismuth Sulphide Thin Films: Synthesis and Characterization. Current Applied Physics, 9, 1140-1145. http://dx.doi.org/10.1016/j.cap.2009.01.003

[24] Yue, G., Tan, F., Wu, J., Li, F., Lin, J., Huang, M. and Zhang, W. (2015) Cadmium Selenide Quantum Dots Solar Cells Featuring Nickel Sulfide/Polyaniline as Efficient Counter Electrode Provide 4.15\% Efficiency. RSC Advances, 5, 42101-42108. http://dx.doi.org/10.1039/C5RA02867A

[25] Scocioreanu, M., Baibarac, M., Baltog, I., Pasuk, I. and Velula, T. (2012) Photoluminescence and Raman Evidence for Mechanico-Chemical Interaction of Polyaniline-Emeraldine Base with ZnS in Cubic and Hexagonal Phase. Journal of Solid State Chemistry, 186, 217-223. http://dx.doi.org/10.1016/j.jssc.2011.12.012 